\title{
Voices of our Students: Using Evidence-based Methods to Inform a Multidis- ciplinary Engineering Program Design
}

\section{Dr. Vicki Stieha, Boise State University}

Vicki Stieha, Ph.D. is a faculty member at Boise State University. She earned her doctorate from the University of Cincinnati. Her current work and research focuses on pedagogical and curricular reform in higher education with special attention to increasing the success of underrepresented students in STEM. She currently serves as the coordinator for Engineering Plus and is a clinical faculty member of the Organizational Performance and Workplace Learning Department in the College of Engineering.

\section{Dr. Noah Salzman, Boise State University}

Noah Salzman is an Assistant Professor at Boise State University, where he is a member of the Electrical and Computer Engineering Department and IDoTeach, a pre-service STEM teacher preparation program. His work focuses on the transition from pre-college to university engineering programs, how exposure to engineering prior to matriculation affects the experiences of engineering students, and engineering in the K-12 classroom. He has worked as a high school science, mathematics, and engineering and technology teacher, as well as several years of electrical and mechanical engineering design experience as a practicing engineer. He received his Bachelor of Science degree in Engineering from Swarthmore College, his Master's of Education degree from the University of Massachusetts, and a Master's of Science in Mechanical Engineering and Doctorate in Engineering Education from Purdue University.

\section{Dr. Amy J. Moll, Boise State University}

Amy J. Moll is a Professor in the Micron School of Materials Science and Engineering at Boise State University. Moll received her B.S. degree in Ceramic Engineering from University of Illinois, Urbana in 1987. Her M.S. and Ph.D. degrees are in Materials Science and Engineering from University of California at Berkeley in 1992 and 1994. Following graduate school, Moll worked for Hewlett Packard (San Jose, Calif. and Colorado Springs, Colo.). She joined the faculty at Boise State as an Assistant Professor in Mechanical Engineering in August of 2000. Along with Dr. Bill Knowlton, Moll founded the Materials Science and Engineering Program at BSU and served as the first chair. From 2011 to 2017, she was Dean of the College of Engineering. Her research interests include engineering education and microelectronic packaging, particularly 3-D integration and ceramic MEMS devices. 


\title{
Voices of our students: Using evidence-based methods to inform a multidisciplinary engineering program design
}

\begin{abstract}
Listening carefully to our students and integrating the variables that matter to them is a step that we can take to increase the number of women and underrepresented minority graduates in engineering. This paper shares an evaluative case study as we report findings from data gathering tools guiding our continuous improvement process. The findings illuminate students' perceptions of their engineering design course and curriculum. We conclude by discussing the pedagogical decisions the teaching team is making as a result of listening to our students' voices.
\end{abstract}

\section{Introduction}

According to a 2012 report from the President's Council of Advisors on Science and Technology, the U.S. needs approximately one million additional science, technology, engineering, and mathematics (STEM) college graduates in order to retain global leadership in science and technology [1]. As of 2017, the 300,000 degrees awarded annually are "only a fraction" of the needed STEM degrees [2]. As has been noted by others [e.g.3, 4], one desirable approach to addressing the U.S. need for additional engineering graduates is to focus efforts on recruiting and retaining women and underrepresented groups into engineering. Accordingly, researchers have been exploring ways to draw more women and underrepresented minorities into STEM and have found that degree flexibility, greater integration of multiple disciplines, authentic learning challenges, and dynamic and collaborative approaches to teaching and learning are all critical to making increases [2]. While not simple, making changes to degree programs so that we can successfully attract and retain a more diverse pool of people who are prepared to provide innovative solutions to $21^{\text {st }}$ century challenges is necessary.

At Boise State University (BSU) we approached the problem of increasing engineering diversity, reducing engineering student attrition, and increasing graduates' professional skills to prepare for a broader array of professional opportunities in STEM related fields as a design challenge. Our primary focus is to attract more women into the degree program with increasing underrepresented minority participation as a secondary goal. In the discussion that follows we will discuss both groups together as underrepresented students, unless we specifically refer to women or minorities. The new flexible curriculum design emphasizes student choice, building competence, and fostering collaboration. At the center of that curriculum are three new engineering design courses, which are the focus of this research.

\section{Background}

Many institutions are focusing on flexibility and engineering design to increase the number of underrepresented people entering engineering and support their success. CU Boulder is a model of a public institution that is seeking to expand student options and increase participation of women and underrepresented minority students through increased flexibility in a design intensive engineering degree program [5]. Stevens Institute of Technology [6] and James Madison University [7] have developed programs incorporating engineering design through all 
four undergraduate years. Highly selective colleges implementing flexible engineering programs include Olin College of Engineering, Dartmouth College, and Harvey Mudd College. These programs are in the top 5 schools with the highest percentage of their bachelor's degrees awarded to women [8]. BSU's approach is informed by the efforts of our institutional peers, adapted to meet the unique culture and resources for our campus, and has been introduced previously [9].

We are guided by the literature as we create a curriculum and employ instructional practices correlated with increasing diversity and inclusion. Thus we have made curricular choices to ensure maximum access and flexibility $[3,10,11]$ to incorporate engineering design with a social good emphasis [12-14], and active learning practices into our courses [24-26].

Engineering Plus is a B.S. degree in Engineering developed with the greatest curricular flexibility that we can provide while also meeting ABET accreditation requirements. Its core develops strong technical skills and essential proficiencies through requisite mathematics, sciences, and engineering sciences courses. Students take a focused set of upper division engineering courses in any of the college's existing engineering disciplines (18 semester credit hours) and create their own pathways through 18 semester credit hours within or outside the college of engineering with the assistance of a faculty advisor. Student choice, the ability to "build your own program" and to tailor a degree to meet students' post-collegiate goals are unique features of the degree. A recent study found that engineering programs, on average, offered students only $4.3 \%$ of the total degree credit hours as open electives compared to $19.8 \%$ for non-engineering degrees [10]. Engineering Plus students will be able to select up to $28.8 \%$ of their electives, a variable that has been correlated with attracting more women and underrepresented minority students to engineering $[15,16]$.

Table 1: Program Degree Requirements

CURRICULUM

General Education Requirements

Mathematics and Science: Calculus I, II, \& III, Diff Equations, Statistics, Chemistry, Physics

Engineering Core Courses: Programming, Graphics, Circuits, Statics, Materials

Introduction \& Engineering Design, I, II, \& III (ENGR 120, 280, 380 \& 480)

Engineering Electives (15 cr. must be upper division)

Pathway Electives (15 cr. must be upper division)
CREDITS

24

32

16

13

18

18

TOTAL

A signature component in this curriculum is the engineering design courses which endeavor to develop student capabilities in human-centered engineering design. When we describe "design" in this curriculum, we mean intentionally creating and improving products, processes and/or experiences. We add human-centered to incorporate the human perspective throughout the design process by adding techniques not generally included in engineering design study. 
Students use these new skills as they apply theories and calculations from the technical core and other courses.

This paper provides an evaluative case study following a prototype semester for the first of three engineering design courses (Engineering Design I, ENGR 280) taught in spring 2018. Our intent in conducting this study was to inform our next steps in the curriculum design process so that we could continue to improve upon elements correlated with increasing diversity and inclusion. We asked the question, how do the curricular features and instructional approaches of the Engineering Design course (ENGR 280 is our present focus) support students' learning and development? Prior to discussing the case study, we detail the theoretical grounding that frames the curricular and instructional design.

\section{Theoretical Framework}

Multiple calls for new approaches to engineering education [1, 2, 13] are linked to 21st century skill sets and the desire to increase diversity in engineering. Studies have demonstrated that traditional teacher-centered pedagogies which emphasize competition and graded feedback and reduce autonomy and intrinsic motivation [17-20] can be off-putting for women and underrepresented minority students, who are often also first-generation college students [21, 22]. In short, traditional approaches are correlated with student departures from STEM [23, 24].

In contrast, studies have demonstrated that learner-centered approaches yield greater student persistence, particularly when comparing the student success rates for women in STEM [24, 25]. Learner-centered strategies emphasize collaboration, critical and creative thinking, and openended problem solving [26] and can increase students' intrinsic motivation to learn.

Our interest in promoting intrinsic motivation through the design spine is directly related to recent scholarship tying these contemporary learning and motivational theories to increased levels of undergraduate student success. Self-determination theory [19] provides a useful lens to explain what motivates undergraduate students to learn, create, and persist in degree programs.

\section{Self-Determination Theory}

Self-determination theory (SDT) describes how "social-contextual factors support or thwart how people are able to thrive given basic psychological needs for competence, relatedness, and autonomy" [27]. Competence refers to the human need to experience mastery and self-efficacy. Relatedness refers to the need for social connection-including feeling cared for and caring for others - and to contribute to a social organization; it is a measure of belonging. Autonomy is the "need to self-regulate one's experiences and actions" [30].

Prior work has demonstrated how self-determination theory can guide curricular and content development resulting in positive outcomes [28-30]. SDT constructs are integral in evidencebased active learning pedagogies including problem-based learning, team-based learning, and other collaborative student-centered pedagogies. These constructs are rooted in relatedness, competence, and/or autonomy. Findings from Trenshaw, Revelo, Earl, and Herman indicate that, in large engineering classes, relatedness was salient to students' motivation [28]. SDT approaches inform supportive interpersonal interactions in post-secondary teaching (e.g., listening to students, empathy, offering praise for performance and constructive feedback, asking 
students what they want or need) [31]. Therefore, faculty can include pedagogies and curricular features that help students see failure as an opportunity to learn or take another approach and not a character flaw or proof of low intelligence [32]. While these active, evidence-based pedagogies are supportive of all students, we are also alert to their potential for increasing the opportunities to support underrepresented students as discussed above.

\section{The Case Study}

We employed an evaluative case study methodology for our inquiry about the specific approach we have taken to designing the engineering design courses for our student population [33]. The data informing this case includes a focus group with five of the six students enrolled in the prototype version of the first of three engineering design courses (ENGR 280) in the Engineering Plus curriculum and their responses to self-determination theory related questions drawn from the Intrinsic Motivation Inventory Scale [34].

The focus group was conducted using a semi-structured interview protocol. The questions were:

- What might I see going on in engineering 280 if I walked in on any given day?

○ How did it compare to your expectations?

- Follow up questions were based on course elements the students described (e.g. lectures, activities, and spaces that they used)

- Please tell me about your engineering design project?

- Tell me about prototyping during the course?

- How would you describe your interactions with one another while working on team projects?

- How would you describe the engineering design process?

Our pilot group of five students agreed to answer the survey during the focus group interview. Given the scope of this evaluative case, we are reporting on the questions related to selfdetermination theory variables (competence, autonomy, and relatedness). We also included effort scale items, as recommended [33]. All the questions include the question stem "in this course" or "during this course" to specify answers that are particular to the ENGR 280 course. The sevenpoint scale is bi-directional with three responses to the negative (somewhat not true, mostly not true, and not at all true) and three to the positive (somewhat true, mostly true, and very true) with neutral as the midpoint of the scale. Due to the very small number of participants, we only are reporting frequencies and are sharing charts to visually represent the trends and to guide methods decisions for collecting responses during the next iteration of the course. The specific questions asked are discussed following the focus group interview data.

Although we present these data in an evaluative case study, this work is part of a larger action research project designed to support a systematic review of the new Engineering Plus curriculum at BSU and its impact on the college's student diversity goals.

The research activities described herein were granted approval by the university's Institutional Review Board and all the invited students provided their consent for their responses to be shared (including verbatim quotes). We have removed identifiers that might convey gender, academic focus, or any other details (including references to the semester) that could be tied to the 
participants due to the size of the program at the time the study took place. We are also mindful to protect the identity of the faculty member teaching the course.

In preparation for the program launch, the faculty team reviewed the literature and studied the curricula of similar programs. We visited the Boulder, CO Engineering PLUS program and sought expert input from a respected peer from Olin College. We engaged in a backward design approach developing program and course outcomes [35] to frame the development of the curricular content and assessment methods. We explained to the students that the course was a "design challenge" and that they had a role as active co-constructors of the course and program.

The course design and setting

We structured the course around the theoretical and process framework of Design Thinking to encourage the students to develop a more user-centered approach to engineering design and to provide a basic structure to the engineering design process. The semester began with The Wallet Project [36] a widely utilized activity designed to introduce design thinking through a fast-paced design and build activity where participants work in pairs to design or reimagine a wallet for their partner in the activity. The class then focused on learning skills associated with engineering design, including problem framing, ethnographic data collection, brainstorming and ideation, prototyping, and fabrication techniques. The students had the opportunity to work with multiple experts from both within and beyond the university community, with expertise in design ethnography, making, and museum exhibit design and fabrication.

The major design challenge for the course involved exploring how people interact with common spaces in the engineering buildings on campus and designing something to make these spaces more engaging or welcoming. The students developed two solutions to this design challenge, one involving a small remotely operated rover display situated near the entrance of one of the engineering buildings, and the other was an interactive stapling station designed for a wellutilized study space in another engineering building. The teams had approximately seven weeks to propose, design, and build their projects. This time frame gave the students enough time to develop a rough prototype but was not enough time to develop reliable functioning solutions for the intended environments.

The course was taught in a new classroom that is part of the university's focus on innovation. The space features write-on surfaces and a glass wall. This classroom is adjacent to the university's makerspace which we hoped would encourage students to develop a creative approach to design. Meeting in this innovation classroom was an intentional divergence from the typical classrooms in which engineering science and analysis courses are taught in the College of Engineering.

\section{The Focus Group}

We approached the focus group designed to help us understand how the students experienced the course and to help us discern their perception of the SDT informed curriculum. Our focus group conversation was conducted by Vicki Stieha who was not teaching the course but is part of the faculty team for the program, hence is familiar to the students. Five students ( 2 women and three men, all of whom are members of the dominant U.S. culture) joined the conversation which lasted approximately 70 minutes. We held the discussion during class in the last week of classes 
when the students were working to wrap up their design projects. While we label the student voices as "Student 1," "Student 2," etc., the labels are not to be read as identifiers and are meant only to indicate the number of dominant voices in each portion of the conversation.

In the following section we share a synthesis of the focus group questions and responses.

Engineering 280 on any given day

The first question asked students "what might I see going on in Engineering 280 if I walked in on any given day?" While the question asked was "what might I see going on..." the responses were more aligned with what the students wanted to do and learn in the course.

The first answer was "It shares a lot of similarities for the first half of the semester with Engineering 120. It has a lot of focuses on like, 'what is Engineering Design."' Engineering 120 is the Introduction to Engineering course that is a prerequisite to ENGR 280 and a first-year course for our students.

The students' initial perception of the course was that it would be very active and that they would be involved in "making" more than they experienced. One student explained:

...that's what I was expecting in this class because it's called engineering design and we were put in the makerspace as a class [others: laughter] so I was like, awesome, we're going to be using this a lot. This is going to be a great design class. [More laughter]. But then we ended up staring at a projector most of the class. It seems like, oh, I'd rather go out there and do stuff.

It was quickly pointed out that ENGR 280 was "a little bit too much" like ENGR 120. They said, "we've already taken ENGR 120, it's a pre-req for this." While all the students agreed that a brief "refresher" on the design concepts from the introduction to engineering course would be good, the course should quickly move into "making." Pointing to the makerspace one said, "let's go use the machines out there." Providing an example of how learning more about design could be built into the first activity of the course, the wallet project [36]. The consensus was that the wallet activity could have been condensed. "Like we spent a few weeks on a wallet on and off and we had a few lessons in between that which were related to design. And then we went on to some other stuff and then, finally, like the week before spring break we went on to our final project."

The students also described a "few lessons...which were related to design" including learning about the voice of the client, empathy, and interviewing. They also were required to train in the machine shop to earn "white and blue tag" competency so they could use the equipment for their design project.

"We are all, like, solid makers"

Talking about what they experienced in the course led them to discuss how they see themselves. One student described the group and none of the others offered an alternative description:

Student A: I think you also have to realize that we are all like, solid makers, and just dive in and do things.... 
Interviewer: I think definitely you are makers...I guess we're not sure if that is just you [this group] or if that's what we'll see in general...

Student A: we're the kind of people who just dive in without any rules and make it up along the way.

The sentiments about who the students "are" and their identity as engineering students, factors into their sense of competence discussed further below. These voices also suggest they have a degree of intrinsic motivation ("dive in" and "make it up" are repeated here).

The students' interests and motivations also surfaced relative to the types of projects they wanted to engage in. When the interviewer asked them, about projects and future work in their next design class, the students were clear, they wanted "real problems" that were "beneficial." One said, "I think I'd be more passionate about the project if it was solving a real problem." Another picked up on that theme saying, "I do agree that it would be a bit more beneficial and a little bit more engaging if we had an actual problem to solve." When asked what types of projects they meant, ideas included projects related to the river near the university, "community issues... [and] affordable housing." A student chimed in, "there's so many different issues in our own community that we could all wrap our heads around to solve." A variety of projects involving recycling and sustainability were mentioned. They wanted "a bigger scale community project that's going to have a lasting impact." From this conversation it appears that, while they enjoy the "making" process, it is not just tinkering, but engineering design for social good that excites this group of students.

How would you describe your experience of working in the makerspace?

While the interview protocol included a question about the makerspace, students' references to wanting more "making" in the course prompted raising the question earlier in the discussion than initially planned.

Student 1: We had an intro and nothing else. [Student 2: Yea.] However, I'm very comfortable using the makerspace on my own and I have used it on my own in the past and I've been a trainer. So, I don't think I am lacking that, but I think other students who had an intro and then no practical projects that would require them to use the space, then the intro might not make sense.

Interviewer: So, you haven't been required to use the makerspace?

Student 3: No. The most we did was a tour. We made a little figurine on the 3D printer and we did some stitches on the sewing machine.

Interviewer: Yeah. I was here that day.

Student 4: But I will say for our project, if we are beginning fabrication this week, we will probably be using it quite a bit. All their wire, soldering... So, it's good for the final project.

Student 1: But we've got one week to get it done. I mean, are you guys nervous? 
Student 2: Nope.

Student 1: I'm so nervous!

Student 3: No. I'm very confident going into this.

While the students' comments suggest they feel competent using makerspace resources, they were less experienced in the engineering machine shop, which raised a concern about competence. One of the assignments for the course was to earn "white tag" and "blue tag" training certification so that they could independently use the power tools and machinery for simple parts fabrication.

Interviewer: and now, what about the machine shop...

Student 1: We're all trained up for the entry level...that's blue tag, right?

Student 2: White and blue tag.

Interviewer: You did the training...did you do any projects; did you do any work in there?

Students [several voices]: No, not for class.

Interviewer: do you think that should be something that...?

Students [several voices]: yea, we should get more experience in there from the class.

Student 2: Yea because you are definitely going to use that for [ENGR] 380 and $480 \ldots$

We spoke briefly about opening the engineering design courses to other majors and their response was supportive indicating that they thought fewer pre-requisites for engineering design courses would help bring in students who have "different skills that they can teach. You kind of learn a little bit of everyone's world." Generally, the students supported the idea of more openness in the curriculum. One student summed the conversation saying, "so, kind of like your design is oriented to working with the skills that you are given. Versus working with everyone having the same background, then all of your projects are going to look the same." In this discussion, the students were referring to homogeneous disciplines (e.g. all mechanical engineers in an engineering design course) and not to race, ethnicity or gender as constituting the "same background."

The next theme involved being able to iterate on a design — starting small, failing, and then adjusting prototype ideas. The students recalled another engineering faculty member's visit to class and her suggestion to prototype using low cost materials ("get a cardboard box and put some remote cars in there and see if people use it") rather than giving the students a big budget to start. They came back to this idea a few times; they want to fail and try again, but they also want a variety of projects.

How do you describe the engineering design process?

As faculty, we were mindful that the course was about engineering design and not tinkering or "making." Although the students' desire to "make" helped them engage in the course and the 
program, it was important to provide a basis in design thinking, user-centered design, and support their upper division courses in engineering design. The students did confirm that the "lectures" in the classroom were about "the design process" and they acknowledged that "doing a refresher" on the design process "would be good." One student offered the suggestion that the faculty could bring "everyone up to date. What is the...expectations of a design process? And then we really get a lot of time to hands on experiment and what worked and what didn't work and prototyping and solving problems."

The discussion about the design process led into a question that one of the faculty wanted to hear them answer. She said, "I want to know how [the students] would describe the design process?" The facilitator explained that the faculty team was interested to know what the students had added to their understanding of the design process during the semester. The ensuing conversation illuminated their understandings:

Student 1: I would describe [engineering design] as a cycle of getting, of finding a problem, gathering information about the problem from talking to people and observing, drawing up some sketches, some prototypes and making things. Um...

Student 2: Understanding constraints. We've done a lot of observations. [Student 1: Yeah.] In this class, but I think it's hard to gain these other skills, without doing and going through with the design from start to finish.

The students also explained that they had an introduction to design ethnography when a faculty member from the Anthropology program came to speak with them about interviewing and observing for user-centered design. They explained the impact of beginning to think about user input through ethnography and how that opened their eyes to more perspectives:

Student: I think I kind of liked it, because it gets you out of that, engineering...like [ENGR] 120 teaches you that design process, but that's a very like, what YOU think is going to be a solution [laughter]. But this class really... like, the ethnography part of it, really gets you thinking about what would someone else do as a solution, what would they want. And I think that was really helpful.

Iteration - of projects and courses

We note the topic of iteration surfaces multiple times in the conversation. The students' frustration about not being able to return to their course project lingers as an unaddressed need. One of the students raises the desire to fail and then improve upon a prototype yet again when the interviewer begins to wrap up the conversation by asking if there are "any other things" the students want to talk to us about. The student says:

You know [another faculty name] in the [Materials Science] Lab...one of the first assignments was this design challenge and then we made our project and then we tested. And I think that was so exciting for me even though my project was an utter failure. Like, I just like going through that process of making something, seeing how bad it was [laughter] and thinking about potential ways to improve it for the future. I guess I was sort of expecting that here. 
The conversation then turned to their ideas about building more opportunities to fail into the course as well as returning to their project prototypes over multiple semesters. However, they were concerned about how the program would add more student to the upper division courses, or if they were "stuck with each other." It was at this moment that the facilitator shared the idea of combining the 280, 380 and 480 courses so that the students would be part of a multiple level team and the students in 380 would have more leadership opportunities as well as be expected to continue building their skills. This idea resonated for the students and they offered similar experiences from high school that they thought could be models. One student offered:

It would be cool if the 280 kids and the 380 kids here sat, like in maybe the same class. Like you had your own projects, like you were a separate class, but if you were overhearing what a 280 kid was saying, you're like, you know I have input on that. Kind of like we have faculty come in and give us input on our presentations. But it would be more like, fluid, like all the time. Like, "here's what we did when we tried that and it worked pretty cool. Maybe you can also do this..."

It was with this conversation that the focus group ended. The students' enthusiastic support for combining the courses provided the faculty with an impetus to iterate on the course structure and to begin conceptualizing an "engineering design studio" with a vertical model and projects that spanned multiple semesters rather than discreet engineering design courses.

\section{Intrinsic Motivation Scale Responses}

As discussed above, we modified questions related to self-determination theory variables including competence, autonomy, and relatedness, with the addition of effort scale items in accordance with recommended practices [33]. As the number of student responses is very small, we share frequency distributions below.

Competence, according to SDT, refers to a sense of accomplishment and self-efficacy related to a focus area [19]. Three questions contributing to the competence construct were, "during this course I felt..."

a. that I was successful in completing difficult tasks.

b. that I was taking on and mastering hard challenges.

c. very capable of learning the material.

As illustrated in Fig. 1, most of the answers to this question were positive with three negative responses to "I felt that I was taking on and mastering hard challenges." 


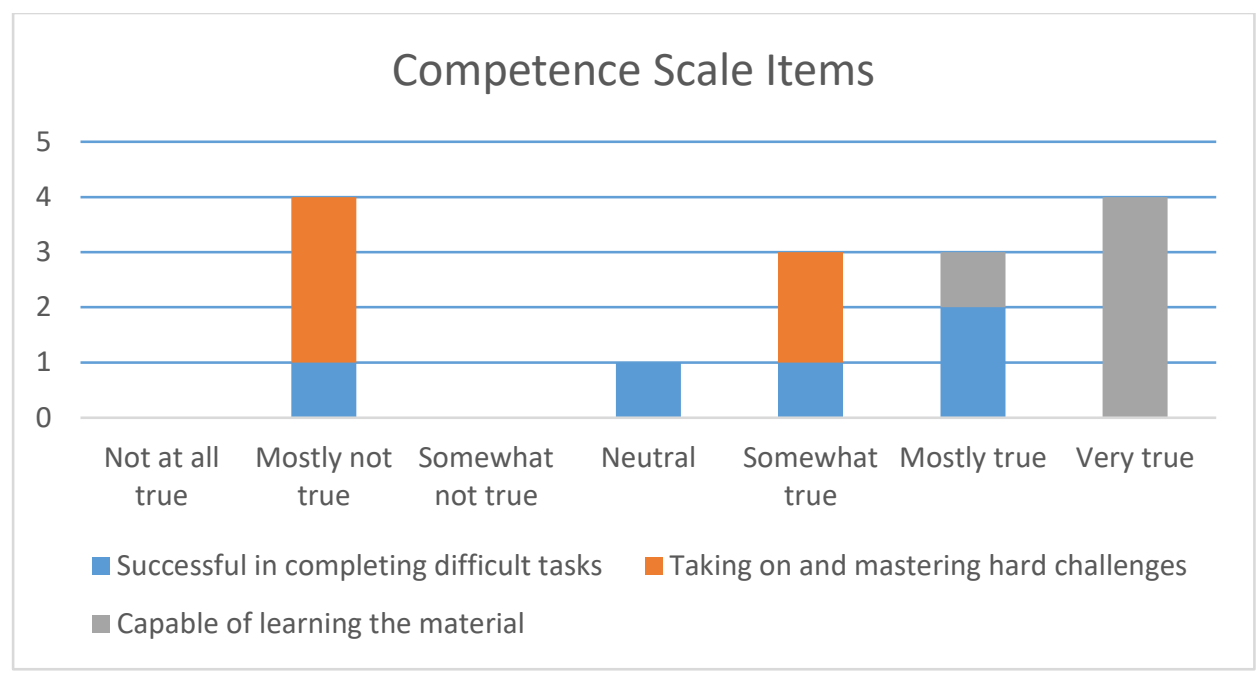

Fig. 1 Competence scale items

We included the effort scale, Fig. 2, which is not central to the SDT, but has been correlated to intrinsic motivation [34] because we are interested to know the level of effort that students attribute to the course. Thus, we included three questions from the scale and found the responses were all relatively positive with two "neutral" responses (one each to effort questions b and c), as shown in figure 2 . These questions included:

a. I put a lot of effort in to this course.

b. I tried very hard on the activities for this course.

c. It was important to me to do well at the activities in this course.

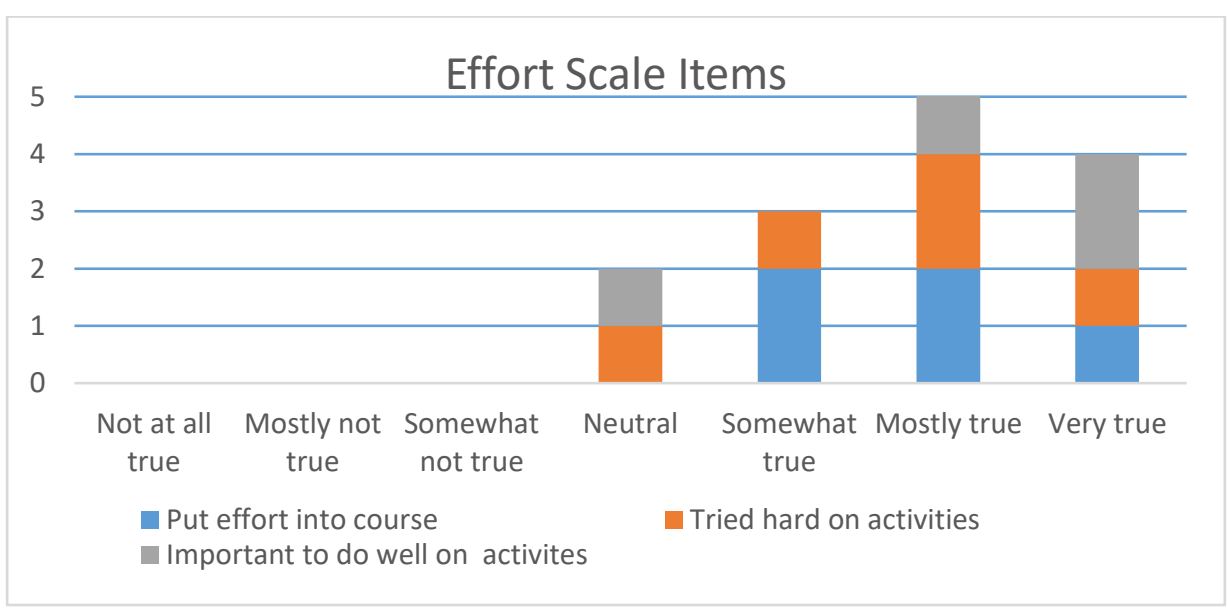

Fig. 2 Student responses on effort scale items

The three autonomy questions in Fig. 3 seek to understand students' sense of their ability to make choices. This variable was a focus for the course design given our review of the scholarship [14-17] while planning the course. The autonomy scale questions included:

a. I believe I had some choices in the activities completed for this course.

b. I felt like I had to take this course (reverse scored to infer taking the course optionally). 
c. I did activities in this course because I wanted to.

When we reverse question b ("I had to take this course"), all the responses clustered with the other autonomy responses on the positive end of the scale, except one (see Fig. 3). As indicated in the background discussion, the course is a requirement for the degree.

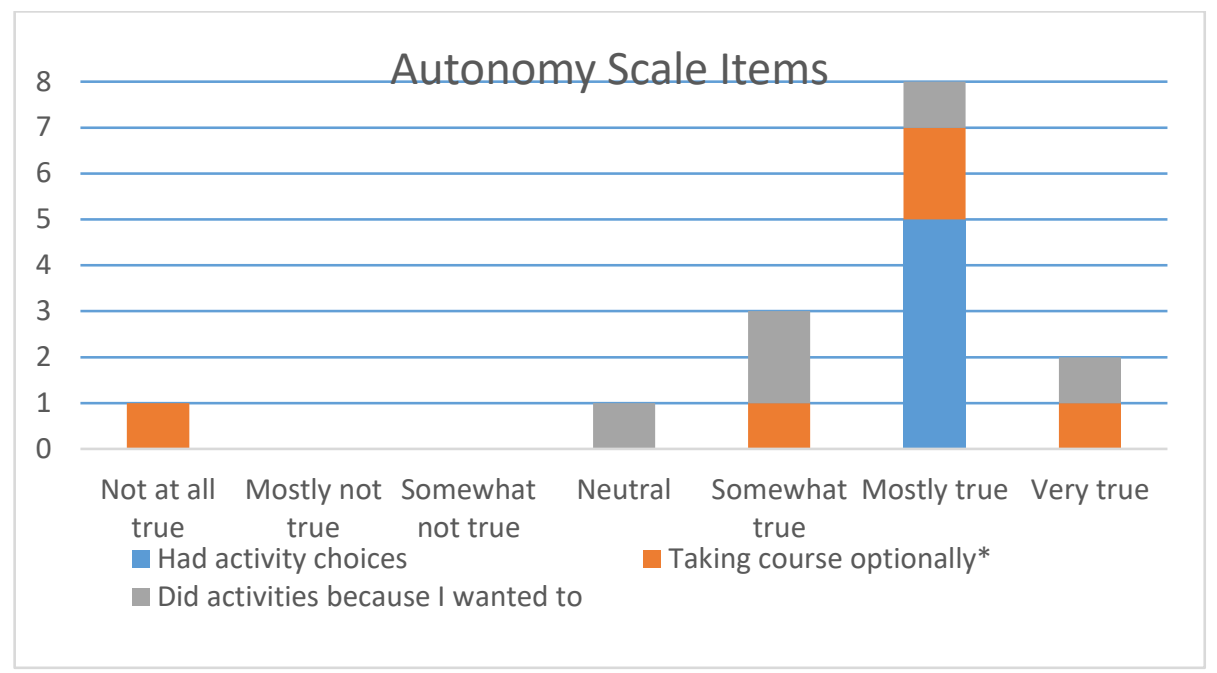

Fig. 3 Students responses to autonomy scale items

Finally, four relatedness questions are included on the scale to measure a sense of connection, interpersonal relationships, and friendship connections among the students. The scholars in engineering education have reported the salience of relatedness to student motivation [28], thus we were interested in this variable in our setting. Compared to the other scales, more students responded "very true" to the relatedness questions, as illustrated in Fig. 4.

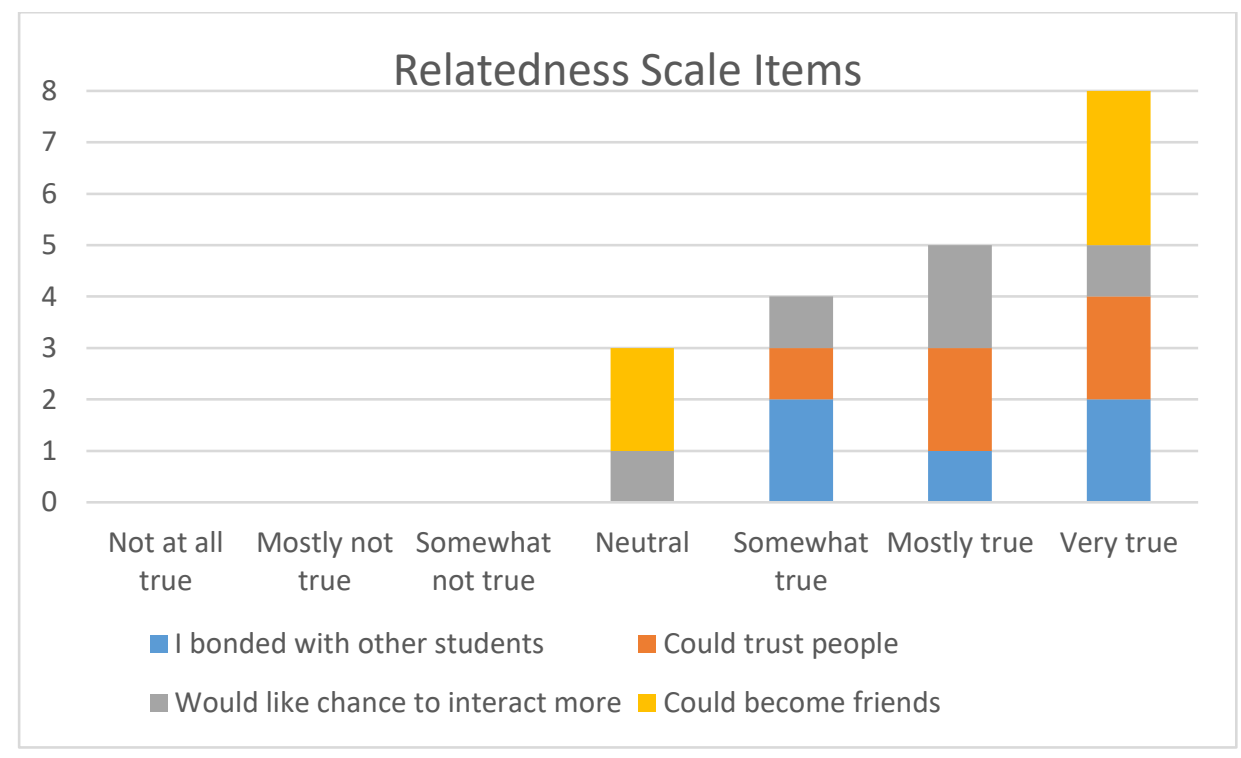

Fig. 4 Student responses to relatedness items 


\section{Faculty Review}

As discussed above, this evaluation case is one component of an ongoing action research project serving our efforts to strategically improve engineering education at BSU while working to attract and retain more underrepresented groups into engineering. After collecting and analyzing these data, the [program name] faculty endeavored to move from evaluation to action.

The student feedback on the pilot course affirmed our intention to move more quickly from a theoretical foundation in user-centered design to engage students in real design challenges with external stakeholders. We decided that we could use hybrid teaching approaches to present background content through active learning pedagogies which will increase student engagement $[23,24,28]$ and allow time in the class to be focused on teams working together on the engineering design process. Weekly individual and team assignments were planned to bolster competence and (likely) increase student effort required for the course. Although the very small number of participants completing the intrinsic motivation scale precludes us from drawing conclusions from these data, our perception of competence (Fig. 1) and effort (Fig. 2) scale responses is that we have opportunities to make course improvements in these areas. We endeavor for self-reported effort and students' responses to "taking on and mastering hard challenges" to be more positive when we repeat this measure in the future.

Although before the focus group we were considering combining the courses into a multilevel engineering design studio to accommodate students who began matriculating in other programs and switched to Engineering Plus as upper division students, the focus group data provided a more clear vision for the future state of the engineering design courses. We used these data to inform our next steps toward a vertically integrated design experience [37]. The students' visions of the advanced students providing input based on their prior experiences fueled our thinking about ways to increase learner-centered pedagogies designed to build competence and fuel students' intrinsic motivation.

Our students' voices echoed the research [e.g. 13, 14] that points to the importance of servicetype and social good projects for the students who are drawn to our program. Although our pilot of the first course included a project that was community centered, it was not perceived as a "real" need and lacked the type of empathetic component that has been demonstrated to foster greater engagement for students [12-14].

These data also affirm our commitment to students' active roles in establishing skill building goals. For example, rather than dictate that all students need to work on a defined list of skill sets, student teams will identify the needed skill sets based on their project demands. Our work as faculty will be to help them identify the skills they need to build and to guide them to the resources needed to learn with a careful eye to make sure the students are taking on appropriately challenging tasks. Given the lower response to this important component of competence, the faculty must be mindful to nudge the students if needed. Students' accomplishments in skills and knowledge will be documented in the ways they deem appropriate in an e-portfolio that the program will also use to demonstrate proficiencies to ABET examiners during the program's initial accreditation. 


\section{Limitations}

Case study method has been criticized because its findings are not generalizable [33]. Because our intent was to analyze the first prototype of a new curricular innovation at BSU, we are more concerned with localizing our work and applying these findings to the continuous design of the Engineering Plus degree.

The population for this study was very small and did not include any underrepresented minority students, which is a weakness given our program goals. Still, as discussed above, we are conducting this research in the company of other engineering education researchers who are demonstrating approaches to increase diversity and inclusion in engineering. Sharing our evaluative case study, including our successes and the places we have stumbled, provides more data for the engineering education research community to improve our collective practices.

\section{Future research and conclusion}

As we move into the next phase of our action research project, we will repeat the focus group and Intrinsic Motivation Scale. With increased numbers of respondents, we will be able to validate the survey for our students and setting. We will triangulate these student perceptions to our classroom observations and samples of student work. One member of our faculty team attends the class each week to observe the course in progress and gather data as we move through this second prototype of the courses, now renamed as the Engineering Design Studio.

Our program has grown to include a more diverse pool of students; our 2019 engineering design course includes $40 \%$ (8) women and 20\% (3) underrepresented minorities in a class of 20 students. Given this increased diversity, we can apply the tools we have developed to better understand if and how the curriculum and instructional approaches we are using is supporting women and underrepresented students in the program. We look forward to sharing our continuing research including more student voices and the next phase of our curriculum design challenge.

\section{References}

[1] S. Olson and D. G. Riordan, "Engage to Excel: Producing One Million Additional College Graduates with Degrees in Science, Technology, Engineering, and Mathematics. Report to the President," 2012.

[2] ABET. (2017, 13 Jan). Engineering change: Lessons from leaders on moderninzing higher education engineering curriculum. Available: http://www.abet.org/blog/news/engineeringchange-lessons-from-leaders-on-modernizing-higher-education-engineering-curriculum/

[3] C. Corbett and C. Hill, "Solving the Equation: The Variables for Women's Success in Engineering and Computing," 2015.

[4] J. Reisfeld. (2018) Meet Engineering Plus: The new design-based model for undergraduate engineering education. Magazine of the Society of Women Engineers. 48-54. Available: http://societyofwomenengineers.swe.org/images/swemagazine/2018/SWEConference2018.pdf

[5] M. S. Zarske, J. L. Cunitz, M. H. Forbes, and J. F. Sullivan, "General Engineering Plus: Creating a community in a flexible yet technical engineering degree," in ASEE Annual Conference and Exposition, Seattle, 2015, pp. 26.816.1-26.816.18. 
[6] B. Frank, D. Strong, R. Sellens, and L. Clapham, "Progress with the professional spine: A fouryear engineering design and practice sequence," Australasian Journal of Engineering Education, vol. 19, pp. 63-74, 2013/01/01 2013.

[7] O. Pierrakos, E. C. Pappas, R. L. Nagel, and J. K. Nagel, "A new vision for engineering design instruction: On the innovative six course design sequence of James Madison University," presented at the ASEE Annual Conference \& Exposition, San Antonio, TX, 2012.

[8] B. L. Yoder, "Engineering by the Numbers," ASEE 2016.

[9] N. Salzman, V. Stieha, A. J. Moll, and J. S. Lighty, "Work in progress: Flexibility and professional preparation via a multidisciplinary engineering curriculum," Proceedings of the ASEE Annual Conference \& Exposition, vol. 21583, pp. 1-9, 2018.

[10] M. H. Forbes, A. R. Bielefeldt, and J. F. Sullivan, "The choice opportunity disparity: Exploring curricular choice opportunities for engineering vs. non-engineering majors," in Proceedings of the ASEE Annual Conference \& Exposition, 2015, pp. 1-15.

[11] Changing the conversation: Messages for improving public understanding of engineering. Washington, D.C.: National Academies Press, 2008.

[12] C. Carter, "Let's stop talking about THE design process," in Medium.com vol. 2018, ed, 2016.

[13] L. B. Cavagnaro and H. Fasihuddin, "A moonshot approach to change in higher education," Liberal Education, vol. 102, pp. 8-17, Spring 2016.

[14] C. L. Dym, A. M. Agogino, O. Eris, D. D. Frey, and L. J. Leifer, "Engineering Design Thinking, Teaching, and Learning," Journal of Engineering Education, vol. 94, pp. 103-120, 2005.

[15] S. Parikh, H. Chen, K. Donaldson, and S. Sheppard, "Does Major Matter? A Look at What Motivates Engineering Students in Different Majors. Research Brief," Center for the Advancement of Engineering Education 2009.

[16] L. Dickson, "Race and gender differences in college major choice," Annals of the American Academy of Political and Social Science, vol. 627, pp. 108-124, 2010.

[17] C. Pulfrey, C. Buchs, and F. Butera, "Why grades engender performance-avoidance goals: The mediating role of autonomous motivation," Journal of Educational Psychology, vol. 103, pp. 683$700,2011$.

[18] S. R. Baker, "Intrinsic, Extrinsic, and Amotivational Orientations: Their Role in University Adjustment, Stress, Well-Being, and Subsequent Academic Performance," Current Psychology, vol. 23, pp. 189-202, 2004.

[19] R. M. Ryan and E. L. Deci, "Self-determination theory and the facilitation of intrinsic motivation, social development, and well-being.," American Psychologist, 2000.

[20] E. L. Deci, R. Koestner, and R. M. Ryan, "Extrinsic Rewards and Intrinsic Motivation in Education: Reconsidered Once Again.," Review of Educational Research, vol. 71, pp. 1-27, 2001.

[21] J. Aronson, C. B. Fried, and C. Good, "Reducing the effects of stereotype threat on African American students by shaping theories of intelligence," Journal of Experimental Social Psychology, pp. 113-125, 2002.

[22] C. Steele, Whistling Vivaldi: And other clues to how stereotypes affect us. New York: W.W. Norton \& Company, 2010.

[23] J. A. Gasiewski, M. K. Eagan, G. A. Garcia, S. Hurtado, and M. J. Chang, "From gatekeeping to engagement: A multicontextual, mixed method study of student academic engagement in introductory STEM courses," Research in Higher Education, vol. 53, pp. 229-261, 2012.

[24] E. Seymour and N. M. Hewitt, Talking About Leaving: Why Undergraduates Leave The Sciences. Boulder, CO: Westview, 1997.

[25] M. A. Fox and N. Hackerman, Eds., Evaluating and Improving Undergraduate Teaching in Science, Technology, Engineering, and Mathematics. Washington, D.C.: National Academy of Sciences, 2003, p.^pp. Pages.

[26] M. Weimer, Learner-Centered Teaching: Five Key Changes to Practice. San Francisco, CA: Jossey-Bass, 2013. 
[27] R. M. Ryan and E. L. Deci, Self-Determination Theory: Basic Psychological Needs in Motivation, Development, and Wellness. New York: The Guilford Press, 2017.

[28] K. F. Trenshaw, R. A. Revelo, K. A. Earl, and G. L. Herman, "Using self determination theory principles to promote engineering students' intrinsic motivation to learn," International Journal of Engineering Education, vol. 32, pp. 1194-1207, 2016.

[29] C. Levesque, A. N. Zuehlke, L. R. Stanek, and R. M. Ryan, "Autonomy and competence in German and American university students: A comparative study based on self-determination theory.," Journal of Educational Psychology, vol. 96, pp. 68-84, 2004.

[30] L. Vanasupa, J. Stolk, and R. J. Herter, "The four-domain development diagram: A guide for holistic design of effective learning experiences for the twenty-first century engineer," Journal of Engineering Education, vol. 98, pp. 67-81, Jan 2009.

[31] T. J. Ten Cate, R. A. Kusurkar, and G. C. Williams, "How self-determination theory can assist our understanding of the teaching and learning processes in medical education. AMEE Guide No. 59," Medical Teacher, vol. 33, pp. 961-973, 2012.

[32] D. A. Shepherd, H. Patzelt, and M. Wolfe, "Moving forward from project failure: Negative emotions, affective commitment, and learning from the experience," Academy of Management Journal, vol. 54, pp. 1229-1259, 2011.

[33] J. M. Case and G. Light, "Framing qualitative methods in engineering education research: Established and emerging methodologies," in Cambridge Handbook of Engineering Educaton Research, A. Johri and B. M. Olds, Eds., ed New York: Cambridge University Press, 2015, pp. 535-549.

[34] (2017). Intrinsic Motivation Inventory Scale [web]. Available: http://selfdeterminationtheory.org/intrinsic-motivation-inventory/

[35] D. Fink, Creating Significant Learning Experiences. San Francisco: Jossey-Bass, 2003.

[36] T. Both. (2016, 2 Feb). The Wallet Project [web]. Available: https://dschoolold.stanford.edu/groups/designresources/wiki/4dbb2/the_wallet_project.html

[37] E. J. Coyle, L. H. Jamieson, and W. C. Oakes, "EPICS: Engineering Projects in Community Service," International Journal of Engineering Education, vol. 21, pp. 1-12, 2005. 